\title{
Abnormalities on neurological examination among sheep farmers exposed to organophosphorous pesticides
}

Jeremy R Beach, Anne Spurgeon, Richard Stephens, Tom Heafield, Ian A Calvert, Leonard S Levy, J Malcolm Harrington

\begin{abstract}
Objectives-Organophosphates are effective pesticides which are frequently used in several agricultural settings. Although their acute effects are well characterised, it remains unclear whether long term exposure can damage the human nervous system. This study sought to investigate their long term effects by comparing abnormalities on neurological examination between groups of workers exposed to organophosphates and an unexposed group.
\end{abstract}

Methods-146 exposed sheep farmers and 143 unexposed quarry workers were recruited into a cross sectional study of symptoms and neuropsychological effects of long term exposure to organophosphates in sheep dip. From a symptom questionnaire given immediately after dipping the 10 most symptomatic and 10 least symptomatic farmers were selected. Several months later each of these, along with 10 of the unexposed quarry workers, underwent a standardised neurological examination similar to that which might be used in clinical practice, at a time as remote as possible from recent exposure to organophosphates so as to exclude any acute effects.

Results-All 30 selected subjects agreed to participate. The components of the examination which showed a significant difference were two point discrimination on the dorsum of the hand (symptomatic farmers $22 \mathrm{~mm}$; asymptomatic farmers 13 $\mathrm{mm}$; quarry workers $8 \mathrm{~mm}$ ) and the dorsum of the foot (symptomatic farmers 34 mm; asymptomatic farmers $10 \mathrm{~mm}$; quarry workers $11 \mathrm{~mm}$ ), and mean calf circumference (symptomatic farmers $35.0 \mathrm{~cm}$; asymptomatic farmers $36.3 \mathrm{~cm}$; quarry workers $38.6 \mathrm{~cm}$ ). Overall the prevalence of neurological abnormalities was low.

Conclusions-The differences in neurological examination detected between groups were subtle and their clinical significance was unclear. However, they do suggest evidence of an adverse neurological effect from exposure to organophosphates. Further, larger scale studies will be required before it is possible to confirm or refute the differences detected.

(Occup Environ Med 1996;53:520-525)
Keywords: sheep farmers; organophosphates; neurological examination

Organophosphate based pesticides have become widely used throughout the world, with applications in many areas of agriculture. Although the acute toxicity of these compounds is relatively well known from knowledge of the mechanism of their actions and from published reports of acute poisoning, recent concerns have been expressed that long term low level exposure may also result in adverse effects upon the human nervous system. ${ }^{1-3}$ Anecdotally, there are reports that exposed people may experience poor mental health and other neurological problems, notably difficulties with cognitive functions including memory and concentration. However, objective scientific evidence of this putative effect is scarce, as most studies involved assessment at a time when acute effects might still have been present, or reported long term sequelae of acute poisoning incidents rather than long term low level exposure..$^{4-8}$

Particular concern has been voiced among sheep farmers, many of whom are exposed to organophosphates through the practice of sheep dipping to control sheep scab and other parasites. This involves total immersion of the animals in a solution of a pesticide, and during this procedure there may be considerable exposure from the splashing of dip onto exposed areas of skin, particularly as the use of protective clothing by many farmers in this situation has been found to be very limited. ${ }^{9}$ Thus, sheep farmers comprise a representative group of agricultural workers with potentially substantial exposure to organophosphates.

The study reported here comprised part of a larger study carried out to assess whether long term low level exposure to organophosphates is associated with chronic effects on the human nervous system. In the main study a total of 146 sheep farmers, and 143 quarry workers with no exposure to organophosphates, underwent extensive neuropsychological testing, the results of which have been reported elsewhere. ${ }^{10}$ Quarry workers were selected as an appropriate comparison group for the farmers as they are largely outdoor workers situated geographically in the same areas of Britain as the sheep farmers being tested, but are unlikely to be exposed to agricultural chemicals (providing those with part time farm jobs are excluded). This paper reports the results from a detailed clinical neu-
University of Birmingham,

Edgbaston, Birmingham

Accepted 14 March 1996 
rological examination of a subgroup of this population, comprising 10 sheep farmers with acute symptoms suggestive of organophosphate effects at the time of dipping, 10 sheep farmers without such symptoms, and 10 quarry workers not occupationally exposed to organophosphates.

\section{Subjects and methods SUBJECTS}

Male farmers were recruited into the main study by selecting every 10 th name on registration lists for the Wool Marketing Board within three areas of Britain (Devon, Cumbria, and North Wales). Initial contact was by letter. However, this initially produced a low response $(33 \%)$ and raised concerns that the study population might not be representative of the sheep farming population as a whole. A further sample was therefore recruited with a telephone call for the initial contact, so producing a better response rate $(69 \%)$. Subsequent comparison of the two samples on a range of demographic and exposure variables showed no significant differences except for mean age (telephone sample five years younger) so largely allaying fears of any substantial recruitment bias. Subjects with any known previous neurological disease, or systemic illness with neurological effects-for example, diabetes-were excluded, as were subjects who had had a head injury which had resulted in loss of consciousness for greater than one hour.

Quarry workers were selected from quarries situated in the same geographical areas as those of the sheep farmers. Any who had helped on sheep farms, been involved in dipping, or been otherwise occupationally exposed to organophosphates-for example, spraying to control pests on fruit crops or on verges-were excluded. Although quarry workers might intuitively seem to be an inappropriate control group because of a risk of exposure to agricultural chemicals, it is interesting to note that only 12 possible recruits had to be excluded because of organophosphate exposure or working with sheep.

It was thought that it would be logistically impossible to perform a detailed clinical neurological examination of all sheep farmers taking part in the neuropsychological assessment as each examination required a visit to the subjects home, often several hundred miles from Birmingham, at a prearranged appointment time. Consequently 30 subjects (20 sheep farmers and 10 quarry workers) were selected from within the study population to undergo further examination. All subjects gave written informed consent to their inclusion in the study.

The main study comprised two stages: the administration of a symptom questionnaire immediately before and 24 hours after dipping to identify symptoms similar to those previously described in reports of organophosphate toxicity; and a neuropsychological assessment carried out as long after the previous year's dipping as possible and before the current year's dipping (when there had been no recent exposure). To maximise the probability of identifying any abnormalities that might be attributable to organophosphate exposure, the 10 sheep farmers with the highest symptom scores 24 hours after dipping were recruited, as well as the 10 with the lowest scores. Although these were not necessarily the 10 with the highest exposure, we none the less thought that they represented the group most likely to display neurological abnormalities. Ten quarry workers were also recruited from a single quarry site. The neurological examinations themselves were carried out as part of the second stage of the investigation, at a time remote from recent exposure to organophosphates.

\section{METHODS}

\section{Neurological examination}

Based upon a neurological examination as used in clinical practice, a format was designed to allow a standardised and systematic examination of all subjects. As examinations were usually to take place in the subjects' own homes in the case of sheep farmers and at the quarries in the case of quarry workers, this was designed to require only relatively simple and robust equipment, and was deliberately tailored to detect the types of abnormalities which could be detected by most physicians. The neurological examination was included in a pilot study to establish that the intended study methods were feasible in practice, and was thought to fulfil its intended aims.

Individual appointments were made with subjects by telephone and confirmed by letter. All examinations were performed by a single investigator (JRB) who was unaware, at the time of examination, which farmers were in the symptomatic group, and which the asymptomatic group, although the quarry workers were identifiable. Before examination several standardised questions were included to find details of any relevant current or previous illnesses, medications, family history of neurological illness-for example, muscular dystrophies, hereditary spinocerebellar degenerative diseases, hereditary myopathies, Huntington's chorea-intake of alcohol, or exposure to other potential neurotoxins-for example, other pesticides and farmyard chemicals, lead, mercury, and thallium. The main elements of the examination included:

sensory and motor examination of cranial nerves including:

visual acuity-assessed by Jaeger chart

visual fields-assessed by confrontation

fundoscopy-with hand held ophthalmoscope

sensory examination

fine touch

pinprick (face bilaterally in each of the divisions of the trigeminal nerve: medial and lateral aspects of arm, forearm, palm of hand: dorsum of hand: tips of fingers: medial, lateral, and posterior aspects of thigh calves: dorsal and plantar surfaces of foot: tips of toes: full length of trunk bilaterally) 
vibration-sternum, wrist, ankle

joint position sense-index finger, big toe two point discrimination at tip of index finger, dorsum of hand, tip of big toe, and dorsum of foot

motor examination

muscle bulk-measured with a tape measure at:

upper arm (15 cm above lateral epicondyle) thigh ( $15 \mathrm{~cm}$ above upper border of patella) calf ( $15 \mathrm{~cm}$ below lower border of patella)

muscle tone

power of all main muscle groups

reflexes-biceps, triceps, supinator, knee, ankle, plantar

coordination and balance

gait

cerebellar abnormalities

The farmers were seen in their own homes at individual appointments throughout the working day. Upon arrival the investigator confirmed that the subject had given consent and explained the nature of the intended examination. A suitable private room for examination was then selected which was comfortably warm and included a couch or bed. Occasionally it was necessary to ask subjects to heat a room so that it would be comfortably warm, so ensuring temperature variations would not affect the examination. Subjects were asked to undress to their under-

Table 1 Characteristics of three subject groups

\begin{tabular}{llll}
\hline & $\begin{array}{l}\text { Symptomatic } \\
\text { farmers }(n=10)\end{array}$ & $\begin{array}{l}\text { Asymptomatic } \\
\text { farmers }(n=10)\end{array}$ & $\begin{array}{l}\text { Quarry workers } \\
(n=10)\end{array}$ \\
\hline $\begin{array}{l}\text { Age (mean (SD)) } \\
\text { Right handed (n) }\end{array}$ & $47 \cdot 0(10 \cdot 6)$ & $49 \cdot 2(14 \cdot 0)$ & $40 \cdot 4(12 \cdot 8)$ \\
$\begin{array}{l}\text { Alcohol (median (range), } \\
\text { units/week) }\end{array}$ & 10 & 10 & 9 \\
$\begin{array}{l}\text { Taking prescribed medication } \\
\text { Family history of }\end{array} \quad 1 \cdot 5(0-16)$ & $5 \cdot 0(0-30)$ & $13 \cdot 5(4-30)$ \\
$\quad$ neurological disease & 1 & 2 & 2 \\
$\begin{array}{l}\text { Previous exposure to } \\
\text { neurotoxic chemicals }\end{array}$ & 5 & 0 & 0 \\
\hline
\end{tabular}

Table 2 Results of neurological examination for three subject groups

\begin{tabular}{|c|c|c|c|}
\hline & $\begin{array}{l}\text { Symptomatic } \\
\text { farmers }(n=10)\end{array}$ & $\begin{array}{l}\text { Asymptomatic } \\
\text { farmers }(n=10)\end{array}$ & $\begin{array}{l}\text { Quarry workers } \\
(n=10)\end{array}$ \\
\hline Cranial nerves abnormality (n) & 2 & 3 & 1 \\
\hline $\begin{array}{l}\text { Sensory system abnormality (n): } \\
\text { Fine touch - objective } \\
\text { Fine touch - subjective } \\
\text { Vibration } \\
\text { Joint position sense }\end{array}$ & $\begin{array}{l}1 \\
2 \\
1 \\
1\end{array}$ & $\begin{array}{l}0 \\
0 \\
0 \\
0\end{array}$ & $\begin{array}{l}0 \\
1 \\
0 \\
0\end{array}$ \\
\hline $\begin{array}{l}\text { Two point discrimination } \\
\text { (mm, median (range)): } \\
\text { Index finger } \\
\text { Dorsum hand } \\
\text { Big toe } \\
\text { Dorsum foot }\end{array}$ & $\begin{array}{r}3 \cdot 50(3-10) \\
21 \cdot 75(6-85) \\
8 \cdot 75(4-23) \\
33 \cdot 75(13-85)\end{array}$ & $\begin{array}{r}3 \cdot 00(3-5) \\
12 \cdot 50(3-38) \\
7 \cdot 50(4-16) \\
10 \cdot 25(5-27)\end{array}$ & $\begin{array}{r}3 \cdot 25(3-10) \\
7 \cdot 50(4-20) \\
7 \cdot 25(3-10) \\
11 \cdot 25(4-18)\end{array}$ \\
\hline $\begin{array}{l}\text { Motor system: } \\
\text { Limb circumference } \\
\text { (cm, mean (SD)) } \\
\text { Upper arm } \\
\text { Thigh } \\
\text { Calf } \\
\text { Abnormality (n): }\end{array}$ & $\begin{array}{l}27 \cdot 5(2 \cdot 0) \\
46 \cdot 9(2 \cdot 8) \\
35 \cdot 0(2 \cdot 1)\end{array}$ & $\begin{array}{l}28 \cdot 8(2 \cdot 1) \\
48 \cdot 0(3 \cdot 3) \\
36 \cdot 3(2 \cdot 3)\end{array}$ & $\begin{array}{l}28 \cdot 9(3 \cdot 2) \\
48 \cdot 1(6 \cdot 7) \\
38 \cdot 6(4 \cdot 0)\end{array}$ \\
\hline $\begin{array}{l}\text { Abnormality (n): } \\
\text { Muscle power } \\
\text { Reflexes } \\
\text { Gait } \\
\text { Coordination } \\
\text { Rombergism } \\
\text { Reflex score (median (range)) }\end{array}$ & $\begin{array}{l}0 \\
0 \\
1 \\
0 \\
1\end{array}$ & $\begin{array}{l}0 \\
0 \\
0 \\
0 \\
0\end{array}$ & $\begin{array}{l}0 \\
0 \\
0 \\
0 \\
0\end{array}$ \\
\hline $\begin{array}{l}\text { Reflex score (median (range)) } \\
\text { Biceps } \\
\text { Triceps } \\
\text { Supinator } \\
\text { Knee } \\
\text { Ankle }\end{array}$ & $\begin{array}{l}2(1-3) \\
2(1-3) \\
2(1-3) \\
2(1-3) \\
2(1-3)\end{array}$ & $\begin{array}{l}2(1-3) \\
2(1-3) \\
1 \cdot 5(1-3) \\
2(1-3) \\
2(1-3)\end{array}$ & $\begin{array}{l}2(1-3) \\
1(1-2) \\
1(1-2) \\
2(1-3) \\
2(2-3)\end{array}$ \\
\hline
\end{tabular}

wear before the examination. Each examination took about 60 minutes. Once the examination was completed the investigator discussed any abnormalities with the individual subject and suggested if appropriate that they visit their own general practitioner.

A surrogate measure of cumulative exposure was estimated for all subjects. This was calculated as: the average number of sheep in their flock $\times$ number of dips a year $\times$ number of years using organophosphates (total number of sheep dipped in organophosphate). This was used to assess differences in average exposure between the three study groups. Given the relatively crude nature of this estimate, the small numbers in the sample, and the way the sample had been selected on the basis of symptomatology, we thought it inappropriate to try to correct for other variables and estimate an exposure response relation with these data.

\section{Data handling and analysis}

As soon as possible after completion, data forms were returned to the Institute of Occupational Health. Data were subsequently entered onto a personal computer and verified. Statistical analysis was undertaken with the statistical software package 'Minitab' (State College, PA 16801-3008 USA). For most analyses the study population was categorised into three groups and comparisons were made contrasting the symptomatic sheep farmers, the asymptomatic sheep farmers, and the quarry workers. Where statistical probabilities are quoted they were calculated with $\chi^{2}$ for categorical data, and analysis of variance for continuous data. A non-parametric analysis of variance (Kruskal Wallis test) was used where appropriate.

\section{Results}

Thirty subjects were selected with the criteria defined in the protocol, and all agreed to take part in this element of the investigation. Table 1 shows some characteristics of subjects in each group. The mean ages of the three groups were not significantly different $\left(\mathrm{F}_{2,27}=1 \cdot 34\right.$, $P>0 \cdot 1$ ), and the three groups were not significantly different for right or left handedness, there was only one left handed subject who was one of the quarry workers $\left(\chi^{2} 2 \cdot 069\right.$, df 2 , $P>0 \cdot 1)$. There were no significant differences between the groups for the number of subjects taking prescribed medication, or the number with a family history of neurological disease. Median alcohol consumption was significantly higher among the quarry workers than either group of sheep farmers (H 11.03, df $2, \mathrm{P}=$ 0.004 ), whereas exposure to other toxic chemicals was less frequently reported by the quarry workers than by either group of sheep farmers $\left(x^{2} 7.500\right.$, df $\left.2,0.05>P>0.01\right)$.

Table 2 shows results from the neurological examinations. The overall prevalence of cranial nerve abnormalities was low and there were no significant differences between the three groups. No consistent pattern of cranial nerve abnormality was noted in any group. 
All the sensory examinations except two point discrimination showed no significant differences between groups. In contrast two point discrimination on the dorsum of the hand and the dorsum of the foot did show significant differences between groups. On the dorsum of the hand median distance between two points before they could be discriminated as separate was $22 \mathrm{~mm}$ for the symptomatic sheep farmers, $13 \mathrm{~mm}$ for the asymptomatic sheep farmers, and $8 \mathrm{~mm}$ for the quarry workers ( $\mathrm{H} 9.07$, df $2, P=0.011$ ); and on the dorsum of the foot the corresponding figures were $34 \mathrm{~mm}$ for the symptomatic sheep farmers, $10 \mathrm{~mm}$ for the asymptomatic sheep farmers, and $11 \mathrm{~mm}$ for the quarry workers $(\mathrm{H} \mathrm{13.22,} \mathrm{df} 2, \mathrm{P}<0.001)$. Two point discrimination was also tested on the index finger and the big toe, and here too the symptomatic sheep farmers required the greatest median distance between two points before they could be discriminated as separate, although these differences were not significant (for index finger $\mathrm{H} 1 \cdot 28$, df $2 ; \mathrm{P}>0 \cdot 1$; for big toe $\mathrm{H} 2 \cdot 15$, df $2 ; \mathrm{P}>0 \cdot 1$ ).

Muscle power was normal for all subjects, and reflexes showed no definite abnormality. No obvious muscle wasting or hypertrophy was noted. Mean calf circumference differed significantly between groups, being $35.0 \mathrm{~cm}$ for the symptomatic sheep farmers, $36.3 \mathrm{~cm}$ for the asymptomatic sheep farmers, and 38.6 $\mathrm{cm}$ for the quarry workers $\left(\mathrm{F}_{2,27} 3.87, \mathrm{P}=\right.$ 0.033 ). Mean circumferences of the upper arm and thigh were not significantly different between groups. Tendon reflexes were scored from 0 to 3 and the median score showed no significant difference between the three subject groups for any of the reflexes tested. No subject had an abnormal plantar reflex, and no subject showed any abnormalities of coordination to suggest a cerebellar abnormality.

One subject in the group of symptomatic farmers had an abnormal wide based gait, and the same subject also displayed rombergism and abnormal joint position sense. Contact with his general practitioner showed that he had been seen some 10 years previously by a consultant neurologist with the same physical signs, but that no cause had been identified at the time, and there had been little if any clinical deterioration in the interim. He had continued to work normally throughout. The clinical significance of these abnormalities was, therefore, not clear.

The change in symptom scores between the questionnaires administered immediately before and 24 hours after dipping was calculated for each group of subjects. The symptomatic group showed an increase in median symptom score in the interval between these two tests from 22.5 to 33.0 , whereas the asymptomatic group showed a decrease from a median symptom score of 3.0 to $1 \cdot 0$. The change in symptom scores was not significantly different between the two groups of sheep farmers.

The surrogate estimate of cumulative exposure, not surprisingly, showed a clear difference between the study groups, as all quarry workers with exposure to organophosphates had been excluded ( $\mathrm{H} \mathrm{17} \cdot 7$, df $2, \mathrm{P}<0.001)$. Median (range) exposure for quarry workers was $0(0-0)$ sheep dipped in organophosphate, for the symptomatic sheep farmers 14500 (1200-180 000), and for the asymptomatic sheep farmers 15000 (300-81 000). However, once the quarry workers were excluded, there were no significant differences in exposure between the two groups of sheep farmers.

\section{Discussion}

This study has identified significant differences between the three subject groups, although these were limited to two point discrimination on the dorsum of the hand and the foot, and the circumference of the calf 15 $\mathrm{cm}$ below the lower border of the patella. No other significant differences were identified in the other variables assessed.

The differences in two point discrimination were significant at two sites, and results at the other two sites tested also showed a non-significant trend with the symptomatic sheep farmers requiring the greatest median difference between two points before they could be perceived as separate. Thus, these data are consistent with the suggested abnormality in two point discrimination in the symptomatic farmers. However, the evidence of an effect on muscle mass is rather less convincing, with only one of three sites tested showing a significant difference between the study groups. Also, data on weight was not available for all subjects and so it was impossible to allow for the effect of body mass index on these measurements. Consequently we would be less confident that this result represents a meaningful difference between groups.

A clear relation was not found between exposure and the neurological abnormalities detected within the groups of farmers. Although there were differences detected in the neurological tests between the two groups of farmers, differences in exposure were not significant. However, the estimate of exposure used was relatively crude, and it may also be that individual susceptibility to the effects of organophosphates was an important factor in determining outcomes, in a similar way that atopy is important in determining the development of occupational asthma in some settings. Variation in susceptibility to the effects of organophosphates between people has been noted to be considerable. ${ }^{1}$ For this study, the symptomatic farmers were selected deliberately because they were the group most likely to have neurological abnormalities, so making the study as sensitive as possible. However, it may be that the differences in neurological outcome reflect constitutional differences between the groups of farmers as well as differences in exposure between the farmers and quarry workers.

There is little evidence that the differences between the groups could have been due to an artefact or to confounding. All examinations were carried out by a single investigator who was unaware of the symptom score of the farmers, and a standardised examination for- 
mat was used for all subjects. Subjects with current or previous disease likely to cause neurological abnormalities were specifically excluded from the study population. The mean ages of the groups were not significantly different, and there were no differences between groups in the prevalence of a family history of neurological disease, or use of prescribed medication. Although the quarry workers were all seen at the workplace rather than their own homes, the room used was private and kept at a comfortable temperature. As with the sheep farmers, examinations were carried out throughout the day. Also, the sheep farmers drank less alcohol than the quarry workers and so should have had fewer abnormalities which could be attributed to this particular cause. Significantly more of the sheep farmers had worked with other potentially toxic chemicals than the quarry workers, most had carried out occasional knapsack spraying of weeds or treating livestock with other chemicals or drugs, for example, equipment cleaning by dairy farmers. The use of these chemicals was however no more prevalent among the symptomatic than the asymptomatic sheep farmers (five subjects in each group recorded their use) although there were clear differences in two point discrimination between the two groups. Consequently it seems unlikely that differences between groups in the use of other chemicals could explain the differences in two point discrimination. Thus, the differences between groups would seem to be genuine, and seem most likely to be due to exposure to organophosphates.

Two point discrimination is the ability to perceive two simultaneous stimuli composed of two blunt points applied to the skin. Normally the ability to measure two points as separate varies between parts of the body, from around $5 \mathrm{~mm}$ for most people on the fingers, but up to about $50 \mathrm{~mm}$ on the dorsum of the foot. In the presence of normal peripheral nerve function disturbance of two point discrimination indicates parietal cortex dysfunction, much like the complex sensation of graphaesthesia. ${ }^{11}$ In our subjects graphaesthesia was not tested but there were no other features suggesting parietal dysfunction, and so a peripheral and neuropathic aetiology seems the most likely explanation for the differences detected in two point discrimination. Muscle wasting is usually a consequence of abnormality in the lower motor neurone, the neuromuscular junction, or the muscle itself (outside the central nervous system). It could therefore be postulated that both abnormalities could be ascribed to a peripheral neuropathy caused by demyelination or an axonopathy (as has been described before in association with organophosphate compounds).$^{812}$ However, if this is the mechanism, it is difficult to understand why only two point discrimination should be affected and not other sensory functions, nor why two point discrimination at other sites was not affected, if such a mechanism were the basis of the abnormalities. It may be that this discrepancy is due to the small number of subjects and hence lack of power in the study, particularly when trying to identify abnormalities in the other sensory functions, none of which were measured as a continuous variable.

Acute symptoms of organophosphate poisoning are generally held to be due to inhibition of cholinesterase enzymes. Classically the symptoms of acute intoxication include nonspecific symptoms such as headache, giddiness, nausea; autonomic symptoms such as blurred vision, miosis, salivation, sweating, and bradycardia; and symptoms related to over-reactivity of volountary muscle - tremors and impaired coordination ${ }^{13}$. The pathogenesis of any putative chronic effects is not so well characterised, and few previous studies have included a neurological examination of subjects exposed to organophosphate pesticides. When this has taken place the examination is rarely described in detail, and only one has reported two point discrimination. ${ }^{612} 14-17$ Because of a lack of standardisation it is difficult to perform comparative analysis of these findings, although several abnormalities have been described.

Davignon et al found a greater proportion of subjects with miosis, weakening or loss of reflexes, tremors, and disturbances of equilibrium among those with contact with insecticides than those without such contact in their study. ${ }^{14}$ Tabershaw and Cooper in their follow up of 114 subjects with a previous episode of acute toxicity due to organophosphates found few long term neurological sequelae although they noted that a high proportion of subjects complained of visual problems. ${ }^{15}$ Most of these complaints however consisted of blurred vision, were in subjects aged 40-55, and consisted solely of presbyopia. The authors concluded that the evidence "leads us to discount the likelihood of any causal relation in these cases between organic phosphate intoxication and permanently disturbed vision". Metcalf and Holmes, although unable to show any clear excess of neurological abnormalities in their group of subjects exposed to organophosphates concluded "It is our impression that exposed men show more so-called "soft" neurological signs such as minor coordination deficits and oculomotor imbalance" ${ }^{16}$ Lotti et al described a delayed neurotoxic effect of organophosphates characterised by a distal motor polyneuropathy, whereas Senanayake and Karalliedde described an intermediate syndrome characterised again by motor abnormalities, predominantly muscle weakness but with changes in reflexes and dystonia also reported in some patients. ${ }^{12} 17$ Savage et al did report two point discrimination in 100 subjects at a variable interval after acute organophosphate intoxication, and 100 controls. ${ }^{6}$ However, no significant differences were found between cases and controls for any test of the sensory system, the only difference found being for one test of motor reflexes. There are no other reports of disturbances of the kind reported here in a chronically exposed population.

Where neurological abnormalities have been found, either acutely, in the intermediate syndrome, or as a part of a delayed polyneu- 
ropathy, they have primarily involved the motor system rather than the sensory system, and this study is unusual in that the major deficit seems to be sensory rather than motor. Most published work reports a motor neuropathic deficit and myelopathy which are known to predominate clinically in cases of acute intoxication. However, there were significant differences between previous populations studied, and the population in this investigation, particularly the nature of exposure of subjects in this study. Most previous investigations have studied subjects after an episode of acute intoxication, usually sufficient to require medical attention, whereas for this study such subjects were specifically excluded. It may be however, that some of the sheep farmers had sustained effects from subclinical episodes of acute intoxication rather than having only long term low level exposures. From these data there is no way to differentiate the effects of these two separate patterns of exposure, and it may be that either or both are capable of causing the changes we have documented.

Although the number of subjects examined in this study is relatively small, these abnormalities cannot easily be dismissed as inconsequential. The combination of findings, although they do not easily fit into any characteristic pattern of neurological disease, are suggestive of neurological dysfunction of a probable neuropathic and peripheral aetiology, although they may represent a combination of both neuropathic and spinal cord dysfunction. Regardless, they suggest that some neurological changes, albeit relatively subtle, had occurred as a consequence of long term exposure to organophosphate sheep dip at concentrations which had never induced sufficient symptoms that medical attention was sought. Sequential examination and additional neurophysiological testing in this group would be of great interest. It may also be helpful to further characterise the exact nature of this neurological abnormality, and determine whether this damage is associated ultimately with any clinical disease.

This work was funded by a grant from the Health and Safety Executive.

1 Gallo MA, Lawryk NJ. Organic phosphorous pesticides. In: Hayes Jr WJ, Laws Jr ER, eds. Handbook of pesticide toxicology, (vol 2), classes of pesticides. San Diego: Academic Press, 1991.

2 Davies JE. Neurotoxic concerns of human pesticide exposures. Am f Ind Med 1990;18:327-31.

3 Mearns J, Dunn J Lees-Haley PR. Psychological effects of organophosphate pesticides: a review and call for research by psychologists. F Clin Psychol 1994;50:286-94.

4 Maizlish N, Schenker M, Weisskopf C, Sieber J, Samuels $S$. A behavioural evaluation of pest control workers with short-term, low level exposure to the organophosphate diazinon. Am F Ind Med 1987;12:153-72.

5 Rodnitsky RL, Levin HS, Mick DL. Occupational exposure to organophosphate pesticides. Arch Environ Health 1975;30:98-103.

6 Savage EP, Keefe TJ, Mounce LM, Heaton RK, Lewis JA, Burcar PJ. Chronic neurological sequelae of acute organophosphate pesticide poisoning. Arch Environ Health 1988;43:38-45.

7 Rosenstock L, Keifer M, Daniell WE, McConnel R, Claypoole $K$. The pesticide health effects study group. Chronic CNS effects of acute organophosphate intoxication. Lancet 1991;338:223-7.

8 Steenland K, Jenkins B, Ames R, O'Mallery M, Chrislip D, Russo J. Chronic neurological sequelae to organophosphate pesticide poisoning. Am $\Im$ Public Health 1994; 84:731-6.

9 Niven KJM, Scott AJ, Hagen S, Waclawski ER, Lovett M, Cherrie B, et al. Occupational hygiene assessment of sheep dipping practices and processes. Edinburgh: Institute of Occupational Medicine, 1993. (IOM report TM/93/03.)

10 Stephens R, Spurgeon A, Calvert IA, Beach J, Levy LS, Berry H, Harrington JM. Neuropsychological effects of long-term exposure to organophosphates in sheep dip. Lancet 1995;345:1135-9.

11 Bickerstaff ER, Spillane JA. Neurological examination in clinical practice, Sth ed. Oxford: Blackwell Sci Publ, 1989.

12 Lotti M, Becker CE, Aminoff MJ. Organophosphate polyneuropathy: pathogenesis and prevention. Neurology

13 Health and Safety Executive. Biological monitoring of workers exposed to organo-phosphorous pesticides, 2nd ed. London: exposed to organo-phosphorous pesticides, 2nd

14 Davignon LF, St-Pierre J, Charest G, Tourangeau FJ. A study of the chronic effects of insecticides in man. Can study of the chronic effects of
Med Assoc $\mathcal{F} 1965 ; 92: 597-602$.

15 Tabershaw IR, Cooper CW. Sequelae of acute organophosphate poisoning. 7 Occup Med 1966;8:5-20

16 Metcalf DR, Holmes JH. EEG, psychological, and neurological alterations in humans with organophosphate exposure. Ann NY Acad Science 1969;160:357-65.

17 Senanayake $N$, Karalliedde $L$. Neurotoxic effects of organophosphorous insecticides. An intermediate syndrome. $N$ Engl $₹$ Med 1987;316:761-3. 